\title{
PREFACE
}

\section{Dialect-Free Assessment Principles}

$\mathrm{I}_{\mathrm{t}}$ is a very great pleasure to introduce this issue of Seminars in Speech and Language, dedicated to the concept of dialect-free assessment principles. The articles collected for this issue thoroughly explore the need for such assessment, and the highly sophisticated measures taken to develop a wide array of experimental measures capable of assessing phonology, syntax, and discourse across widely varying dialect communities in the United States. It is noteworthy that the development of these measures did not capitalize on differences among dialect communities, but upon their commonalities, some of which are not readily apparent to the practicing speech-language pathologist.

Older approaches to the assessment of children not present in original normative samples for commonly used diagnostic inventories included several options, including alternative response sets and local norms. By focusing intently on advances in normal child language acquisition, editors Seymour and Pearson and their colleagues were able to isolate tasks capable of identifying not only dialect usage but also disordered language ability across dialect communities, a goal that has not easily been achievable until this point.

We have taken advantage of their teamwork to present a series of articles that map the journey to their proposed solution to the challenge of dialect-free assessment. Our intent is to share the developmental thought process with readers, so that they might appreciate the challenges, potential solutions, and validation steps inherent in this ambitious project. As a narrative of the problem-solving process in a difficult area of assessment, I find this collection of articles to be thought provoking, insightful, and, most importantly, extraordinarily helpful in clarifying an otherwise cloudy concepthow to discriminate between language variation and language disorder.

Nan Bernstein Ratner, Ed.D. Co-editor in Chief ${ }^{1}$ 